\title{
Adrenal function in patients with active tuberculosis
}

\author{
DAVID J BARNES, SIRUS NARAQI, PUKA TEMU, JOHN R TURTLE \\ From the Department of Clinical Sciences, University of Papua New Guinea, Port Moresby, Papua New Guinea, \\ and the Department of Medicine, University of Sydney, Australia
}

\begin{abstract}
Although tuberculosis is a recognised cause of adrenal insufficiency, little is known about adrenal function in patients with active tuberculosis. Ninety Melanesian adults with active tuberculosis (30 pulmonary, 30 miliary, 30 extrapulmonary) had adrenal function assessed prospectively before and three to four weeks after starting antituberculous chemotherapy. Basal serum cortisol concentrations were normal in $55(61 \%)$ and raised in $35(39 \%)$ of the subjects. No patient had a low basal cortisol concentration. After Synacthen stimulation, cortisol responses were normal in $81(92 \%)$ of the patients and subnormal in seven (8\%). After antituberculous chemotherapy the response to Synacthen stimulation was normal in all but one patient. It is concluded that adrenal dysfunction is an uncommon problem in patients with active tuberculosis, and that, contrary to recent reports, antituberculous chemotherapy regimens that include rifampicin do not have an adverse effect on adrenal function.
\end{abstract}

\section{Introduction}

Tuberculosis is a recognised cause of adrenal failure. In a review of necropsy findings in $\mathbf{4 0 3}$ patients with Addison's disease from 1900 to 1929 tuberculosis of the adrenals is said to have been found in $69.7 \%$ of cases. ${ }^{\prime}$ As the incidence of tuberculosis in developed countries has declined, its importance in the aetiology of Addison's disease has diminished..$^{2-4}$ Far less is known, however, about adrenal function in patients with active tuberculosis nor is it known whether adrenal function varies in these patients according to the extent of their disease.

We sought therefore to determine the state of adrenal function in a prospective study of patients with active tuberculosis. The effects of disease extent and antituberculous chemotherapy were investigated.

\section{Methods}

Ninety Melanesian adults admitted with active tuberculosis to the university hospital in Port Moresby, Papua New Guinea, were studied prospectively. They were divided into three groups according to the extent of their disease. Each group consisted of 30 con-

Address for reprint requests: Dr David J Barnes, RPAH Medical Centre, 100 Carillon Avenue, Newtown, New South Wales 2042, Australia.

Accepted 3 February 1989 secutive patients who fulfilled the criteria for that group:

Pulmonary These patients had radiographic evidence of either a pulmonary infiltrate (not a miliary pattern) or a pleural effusion, sputum positive for acid fast bacilli (direct smear or culture) or histological evidence of tuberculous pleuritis from pleural biopsy, and no evidence of extrapulmonary spread.

Miliary All patients had a typical miliary pattern on their chest radiographs. The presence or absence of extrapulmonary spread did not affect the classification of a patient as having miliary disease. Histological or microbiological confirmation (or both) of tuberculosis was made in 25 cases; in the remaining five the diagnosis was made from typical radiographic and clinical features, and from the response to antituberculous chemotherapy.

Extrapulmonary This group includes patients with lymph node (12), peritoneal (11), bone (6), and genitourinary (1) tuberculosis. The diagnosis was confirmed in 23 cases, either histologically or by demonstration of acid fast bacilli by direct smear or culture. The other seven patients had clinical features consistent with tuberculosis and improved with antituberculous treatment.

On entry into the study all patients had the following investigations: (1) serum sodium $\left(\mathrm{Na}^{+}\right)$and potassium $\left(\mathrm{K}^{+}\right)$concentrations; (2) basal serum cortisol concentration, measured at 7.30 and 8.00 am (the basal concentration was taken as the mean of these 
two measurements); (3) a standard Synacthen stimulation test. ${ }^{5-8}$ After the intravenous injection of $0.25 \mathrm{mg}$ Synacthen (synthetic adrenocorticotrophic hormone) at $8.00 \mathrm{am}$, serial serum samples for measurement of cortisol concentration were collected at $\mathbf{3 0}$ minute intervals for two hours.

Antituberculous chemotherapy was then started, which consisted of the four drug regimen isoniazid, rifampicin, streptomycin, and pyrazinamide. Measurements of basal serum cortisol concentration and a Synacthen stimulation test were repeated 20-30 days after the start of treatment.

The mean serum sodium and potassium concentrations for each group of patients were compared by a one way analysis of variance.

\section{Results}

\section{SERUM ELECTROLYTES}

The serum $\mathrm{Na}^{+}$concentration was normal (135-145 $\mathrm{mmol} / \mathrm{l}$ ) in 53 and below normal in 37 patients. Most cases of hyponatraemia were mild, the lowest value being $124 \mathrm{mmol} / \mathrm{l}$. There was no significant difference between the three groups with respect to the prevalence of hyponatraemia. Serum $\mathrm{K}^{+}$concentration was normal $(3.5-4.9 \mathrm{mmol} / \mathrm{l})$ in 63 and below normal in 27 patients. None of the patients was hyperkalaemic. There was no significant difference in serum $\mathrm{K}^{+}$concentration between the three groups.

INITIAL BASAL SERUM CORTISOL

\section{CONCENTRATIONS}

Basal serum cortisol concentrations were normal in 55 patients at the time of diagnosis and raised in 35. No patient had a low basal concentration. Patients with miliary tuberculosis had the highest basal serum cortisol concentrations, 18 of 30 patients having raised concentrations (table 1).

\section{INITIAL SYNACTHEN STIMULATION}

After the parenteral administration of Synacthen, 74 of the 90 patients had a normal cortisol response (that is, an increment of over $200 \mathrm{nmol} / 1$ above the basal concentration). Of the remaining 16 patients with a

Table 1 Basal serum cortisol concentrations before treatment

\begin{tabular}{lllllrl}
\hline & & \multicolumn{2}{l}{ No (\%) of patients with } \\
\cline { 5 - 7 } Subgroup & $\begin{array}{l}\text { Mean (SD) basal } \\
\text { concentration }\end{array}$ & $\begin{array}{l}\text { Normal } \\
\text { values* }\end{array}$ & $\begin{array}{l}\text { Raised } \\
\text { values* }\end{array}$ \\
\hline Pulmonary & 600 & $(206)$ & 22 & $(73)$ & 8 & $(27)$ \\
Miliary & 855 & $(351)$ & 12 & $(40)$ & 18 & $(60)$ \\
Extrapulmonary & 572 & $(161)$ & 21 & $(70)$ & 9 & $(30)$ \\
\hline
\end{tabular}

*Normal range $150-650 \mathrm{nmol} / 1$.
Table 2 Basal serum cortisol concentrations after treatment for 77 of the patients

\begin{tabular}{lllllll}
\hline & & \multicolumn{3}{l}{ No (\%) of patients with } \\
\cline { 3 - 7 } Group & $\begin{array}{l}\text { Mean (SD) basal } \\
\text { concentration }\end{array}$ & $\begin{array}{l}\text { Normal } \\
\text { values* }\end{array}$ & $\begin{array}{l}\text { Raised } \\
\text { values* }\end{array}$ \\
\hline Pulmonary & 498 & $(112)$ & 25 & $(96)$ & 1 & $(4)$ \\
Miliary & 463 & $(190)$ & 22 & $(88)$ & 3 & $(12)$ \\
Extrapulmonary & 468 & $(89)$ & 25 & $(96)$ & 1 & $(4)$ \\
\hline
\end{tabular}

*Normal range $150-650 \mathrm{nmol} / \mathrm{l}$.

subnormal response, nine started with a raised basal serum cortisol concentration. There were therefore only seven patients with normal basal cortisol concentrations who had a subnormal response to Synacthen stimulation. These seven patients consisted of four with extrapulmonary tuberculosis, two with pulmonary tuberculosis, and one with miliary tuberculosis.

\section{CORTISOLS AND SYNACTHEN STIMULATION} AFTER TREATMENT

Seventy seven patients were restudied 20-30 days after starting antituberculous chemotherapy. The remaining 13 patients were not restudied owing to transfer to another health centre (5), self discharge from hospital (5), or death (3). Of the 77 patients restudied, only five had persistently raised basal serum cortisol concentrations; the remainder had concentrations within the normal range. All three groups had lower mean basal serum concentrations than before treatment (table 2).

After Synacthen stimulation all subjects had a normal cortisol response except for one subject, whose increment in serum cortisol was $120 \mathrm{nmol} / \mathrm{l}$.

\section{Discussion}

There is evidence that secretion of the major corticosteroid hormones is stimulated early in the course of acute infectious illness. ${ }^{9-11}$ In contrast, adrenocorticol secretion is generally depressed during chronic infections, including tuberculosis. ${ }^{12-14}$ Few published studies have examined adrenal function in patients with active tuberculosis. A recent report from South Africa ${ }^{15}$ described a suboptimal response to Synacthen in $55 \%$ of African Zulus with acute pulmonary tuberculosis. In these patients antituberculous chemotherapy had a favourable effect on adrenal function, though those who received rifampicin showed less improvement than those who were given regimens that did not include rifampicin. It was postulated that rifampicin, by its effect on hepatic enzyme induction and subsequent increased glucocorticoid metabolism, may disturb adrenal function. ${ }^{16}{ }^{17}$ Our study, however, showed that a regimen that included rifampicin for all patients had a 
favourable effect on adrenal function, only one of 76 patients having a subnormal Synacthen response three to four weeks after starting treatment. The striking difference in results between our study and the African study may be explained by differences in the criteria used to assess abnormal adrenal function. In the study from Africa basal serum cortisol concentrations are not reported, the response to Synacthen was based on only one serum specimen taken one hour after Synacthen injection, and a normal cortisol response was defined as a rise of at least $300 \mathrm{nmol} / \mathrm{l}$ above the baseline value.

Serum $\mathrm{Na}^{+}$concentration was a poor predictor of adrenal function in our study. Hyponatraemia was present in $41 \%$ of patients, yet there was no correlation between serum $\mathrm{Na}^{+}$concentration and either the basal serum cortisol concentration or the response to Synacthen stimulation. We could not investigate the pathophysiology of hyponatraemia any further in these patients, but presumably most cases were due to causes other than hypoadrenalism (for example, salt depletion, inappropriate antidiuretic hormone secretion).

None of our 90 patients had depressed basal serum cortisol concentrations; indeed, $39 \%$ had a raised basal serum concentration, suggesting an appropriate adrenal response to the "stress" of active infection. The nine patients with raised basal concentrations who did not achieve an increment greater than 200 nmol/1 after Synacthen stimulation could not be considered to show evidence of significant adrenal insufficiency. The seven with normal basal serum cortisol concentrations who did not achieve the required increment with Synacthen must, however, be considered as having some degree of adrenal dysfunction. Although the numbers are small, it is worth noting that most $(4 / 7)$ of these patients had extrapulmonary tuberculosis-Pott's disease of the spine (2) and peritoneal (1) and lymph node (1) tuberculosis. The pathogenesis of depressed adrenal function in tuberculosis is not clear, but it is probably related to the chronicity of infection rather than any specific characteristics of mycobacterial infections. Although evidence of tuberculosis affecting the adrenal glands was found in most of the Addisonian patients in the necropsy study quoted above, ' most cases of hypoadrenalism are likely to be due to a functional disorder of the adrenal glands as after antituberculous treatment (and clinical improvement) the Synacthen response returned to normal in all but one patient. This concept of functional hypoadrenalism (or even hypopituitarism) is supported by the results of other studies. ${ }^{12-14}$

We conclude that there is a low but definite incidence of adrenal dysfunction in patients with active tuberculosis. Antituberculous chemotherapy regimens that include rifampicin have a favourable effect on adrenal function.

We wish to thank Simone Nicholson for secretarial assistance in the preparation of the manuscript, and the staff of the endocrinology laboratory at Royal Prince Alfred Hospital for performing the serum cortisol estimations.

\section{References}

1 Guttman PH. Addison's disease-a statistical analysis of 566 cases and a study of the pathology. Arch Pathol 1930;10:742-85, 896-935.

2 Shapiro M, Zalewski S, Steiner Z, Bernheim J, Nabriski $\mathrm{D}$, et al. Adrenal insufficiency in a general hospital over a 14 year period. Isr J Med Sci 1984;20:381-7.

3 Vita JA, Silverberg SJ, Goland RS, Austin JH, Knowlton AI. Clinical clues to the cause of Addison's disease. Am J Med 1985;78:461-6.

4 Nerap J. Addison's disease-clinical studies. A report of 108 cases. Acta Endocrinol 1974;76:127-41.

5 Kehlet H, Blichert-Toft M, Lindholm J, Rasmussen P. Short ACTH test in assessing hypothalamic-pituitaryadrenocortical function. $\mathrm{Br} \mathrm{Med} J$ 1976;i:249-51.

6 Speckart PF, Nicoloff JT, Bethune JE. Screening for adrenocortical insufficiency with Cosyntropin (synthetic ACTH). Arch Intern Med 1971;128:761-3.

7 Bondy PK. Disorders of the adrenal cortex. In: Wilson ID, Foster DW, eds. Williams Textbook of endocrinology. Philadelphia: Saunders, 1985:847.

8 Irvine WJ, Barnes EW. Adrenocortical insufficiency. Clin Endocrinol Metab 1972;1:549.

9 Migeon CJ, Kenny FM, Hung W, Voorhess ML. Study of adrenal function in children with meningitis. Pediatrics 1967;40:163-83.

10 Cornil A, Copinschi G, Leclercq R, Franckson JRM. Cortisol secretion during acute bacterial infections in man. Acta Endocrinol 1968;58:1-5.

11 Melby IC, Spink WW. Comparative studies on adrenal cortical function and cortisol metabolism in healthy adults and in patients with shock due to infections. J Clin Invest 1958;37:1791-8.

12 Shuster S. Functional hypopituitarism of advanced chronic pulmonary tuberculosis. $\mathrm{Br} J$ Tuberc 1957; 51:279-89.

13 Ryback IN. Functional state of adrenal cortex during antibacterial therapy in children suffering from thoracic forms of tuberculosis. Pediatria 1965;44: 8-12.

14 Frenkel JK, Hinshaw CT, Ruth W, Brown R, Bakke JL. Pituitary-adrenal function in chronic pulmonary tuberculosis. Am Rev Respir Dis 1964;89:835-41.

15 Ellis ME, Tayoub F. Adrenal function in tuberculosis. Br J Dis Chest 1986;80:7-12.

16 Edwards OM, Courtenay-Evans RJ, Galley JM, Hunter $\mathrm{J}$, Tait AD. Changes in cortisol metabolism following rifampicin therapy. Lancet 1974;ii:549-51.

17 McAllister WAC, Thompson PJ, Al-Habet SM, Rogers HJ. Rifampicin reduces effectiveness and bioavailability of prednisolone. $\mathrm{Br}$ Med J 1983;286:923-5. 